\title{
Improvement of pseudo-3D pit displacement mapping technique through geodetic prism data integration
}

\author{
M Salvoni Australian Centre for Geomechanics, The University of Western Australia, Australia \\ K Abbott MMG Limited, Australia \\ PM Dight Australian Centre for Geomechanics, The University of Western Australia, Australia
}

\begin{abstract}
In recent years, an innovative approach has been proposed in using two ground-based synthetic aperture radars to simultaneously monitor slope stability (Severin et al. 2011; 2014). The technique allows to obtain a detailed pseudo 3D displacements map covering large pit slopes. In October 2014, a similar experiment was conducted at MMG Limited's Century Mine (Queensland), using two real aperture radars. The outcomes of the test have shown that even if reasonable results can be achieved, more precise information can be obtained through the integration with prism data. The technique has produced a much clearer image of the slope deformation, identifying a complex break-up of the slope surface due to the weathering process affecting the shale rock mass.
\end{abstract}

\section{Introduction}

One of the greatest challenges in open pit mines is to recognise potential for instabilities in order to guarantee safety of personnel and to maximise ore extraction. For most of the mining companies, this is carried out by personnel through the monitoring of surface displacements using visual observations, geodetic prisms, radar, and deep deformations using inclinometers and extensometers (Hawley et al. 2009). Traditionally, surface movements have been monitored using prism data. This offers the advantage of having a wide coverage of the mine and provides accurate information about the magnitude and direction of the movements. However, the technique is limited by the fact that prism data are single point measurements which may be widely spaced (more than $20 \mathrm{~m}$ ). Moreover, targets can be damaged or lost and there may be difficulty having access to the surface and replacing them (Little 2006). For these reasons, more often radar monitoring is becoming increasingly popular in the industry. Radar monitoring allows one to obtain a full coverage of critical areas, in nearly real-time acquisition and high precision.

The technology of the radar is based on the detection of distance and direction by transmitting and receiving electromagnetic waves. The distance is simply evaluated using the difference in time (time of flight) between the transmission and the reception of the signal pulse. On the other hand, the direction estimation depends on the technology used. A first class of radars (real aperture radar) consists of a large high gain antenna, rotating to scan all directions. Another type of radar is the synthetic aperture radar, using a low gain antenna moving along a guide to simulate a large antenna (Pieraccini 2013).

A significant limitation though, independently of the radar used, is that this instrument can only measure the variation of the distance towards it line-of-sight (LOS). This implies that the full 3D direction of movements cannot be obtained and, in the case of complex multi direction instabilities, may lead to partially underestimating the displacements. In order to overcome these limitations, Severin et al. (2014) have proposed an advanced monitoring technique, using two ground-based synthetic aperture radar systems simultaneously. This approach allows the creation of a detailed map of magnitude and direction of displacements for a large open pit rock slope. In October 2014, a similar experiment was conducted at MMG Limited's Century Mine. 
MMG Limited's Century Mine is located near Lawn Hill in North Queensland, Australia, approximately $250 \mathrm{~km}$ northwest of Mount Isa, close to the Northern Territory border. As mining in the southwest (SW) corner commenced, the area of the pit wall has been affected by continuous unravelling on bedding planes. As a precaution, a buttress has been left at the base of the slope in order to prevent additional development of the instability while mining. As Century progresses to the end of the mine plan, mining operations in the area has been completed, with a slope height of $300 \mathrm{~m}$ and overall angle of $40^{\circ}$. Surface deformations were monitored by geodetic prisms and one real aperture radar. Due to the deformation occurring on the wall, local areas of the prism network have been destroyed and surface data of these areas are available only from the radar. The aim of the research was to obtain more detailed information about the direction of movements for those areas of the pit wall.

\section{SW wall rock slope instability}

\subsection{Geotechnical setting}

The SW wall is developed within the footwall sequence and is characterised by three main geotechnical units: lower footwall (LFW), upper footwall (UFW) and carbonate breccia domain (CBX) (Figure 1). The LFW is dominated by black carbonaceous shales, a tight and fair rock mass with distinctive bedding but indistinct other structures. In comparison, the UFW comprises black laminated shales, a more competent rock mass with distinctive laminated bedding (Hendersonhall et al. 2010). Both shale types exhibit highly anisotropic behaviour, are low strength rocks ( $30 \mathrm{MPa})$, and are affected by continuous fracturing and occasional bedding shears (Kurukuk \& Sweeney 2012). Pandora's fault, a deposit scale major structure, represents the boundary between these two domains. Moreover, along this fault a massive block of intrusive carbonate breccia (CBX) outcrops. The presence of discordant veins of breccia along pre-existing fractures/faults is not unusual at Century, with widths varying from 0.1 to 34 metres (Waltho \& Andrews 1993).

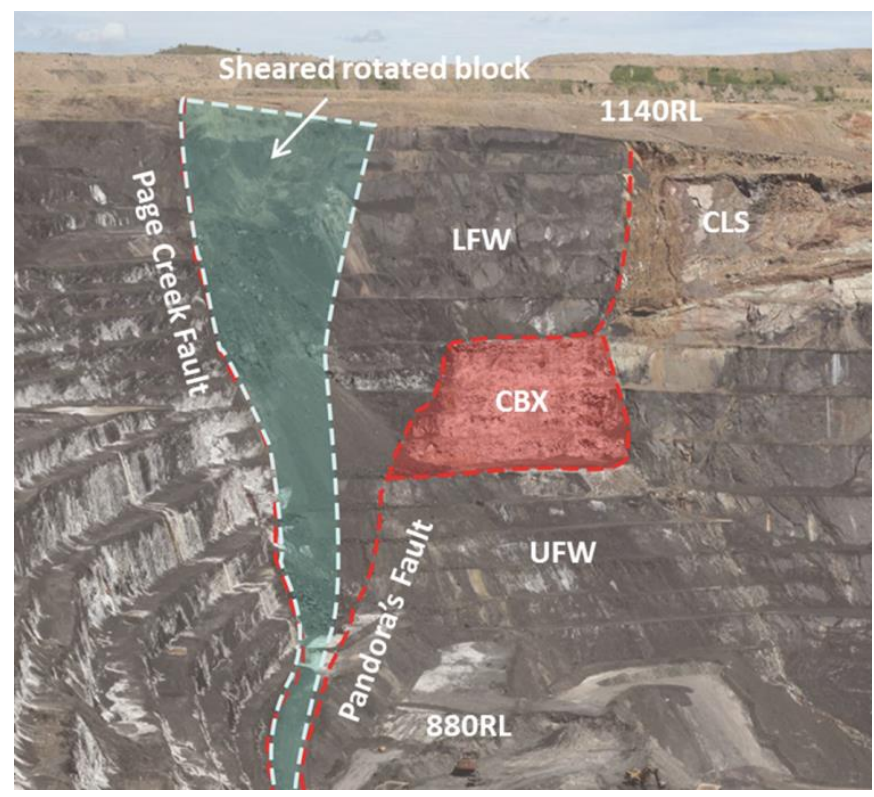

\section{Figure 1 Overview of SW wall (modified from MMG Limited geotechnical team)}

Pandora's fault represents one of the dominant geological structures in the SW corner. It is a gently to moderately north dipping, east-west (EW) striking normal fault, which displaces the ore body into two major blocks. It has been interpreted as a scissor fault, with displacement varying along the strike from zero at the eastern margin of the deposit to over $300 \mathrm{~m}$ at the western margin (Broadbent et al. 2002). However, in the SW corner, Pandora's Fault displays a sharp change in orientation from a strike of EW to north-west (NW). The area is also characterised by the presence of a set of EW striking north dipping subvertical structures. One of those structures, known as Page Creek Fault, has contributed to the local 
rotation of bedding and joint sets, resulting in the formation of a highly sheared and fractured block (Kurukuk \& Sweeney 2012).

\subsection{Current prisms and radar monitoring}

Surface monitoring is performed throughout 80 geodetic prisms and one ground-based real aperture radar (Figure 2). Looking at the areas where the majority of displacements are concentrated, the prisms network is particularly well spaced around the crest of the pit and the CBX block, while part of the slope is not covered and data are only available from the radar unit.

Historically, the pit wall is particularly active during the wet season, between November and March, with the total amount of displacement reaching up to several metres. During the dry season, the residual rates of movement are around $1 \mathrm{~mm}$ per day. The largest deformations are concentrated in the top part of the pit wall and in the CBX block, while the buttress has not shown any significant movements outside of localised small scale instabilities. Geotechnical investigations have outlined that those movements are related to wedge/sliding mechanisms along bedding planes, associated with stress release along faults and joint sets (Kurukuk \& Sweeney 2012). Parts of the instability have been reduced by the presence of the CBX block, acting as a natural buttress and slowly being pushed out in a toppling manner.

A clear image of the surface deformations has been obtained by combining information from both prism and radar monitoring. In Figure 2, as an example, data recorded from 1 to 6 March were imported and visualised using the software mXrap 4.1.9 (Harris \& Wesseloo 2015). The image obtained allows one to identify at least four homogeneous zones, based on the direction and magnitude of displacements (Table 1).

Moreover, for each area an evaluation of the underestimation of the radar measurements was determined, projecting the displacement vector from the prisms along the LOS though the following formula:

$$
P=\frac{u * v}{\|v\|^{2}} * v
$$

where:

$$
\begin{aligned}
& P \quad=\text { projection of vector } u \text { on } v . \\
& u \quad=\text { displacement vector from prism. } \\
& v \quad=\text { LOS vector. }
\end{aligned}
$$

Table 1 Summary of underestimation of radar measurements for different areas

\begin{tabular}{ccccc}
\hline$\#$ & Area & \multicolumn{2}{c}{ Displacement vectors* } & Average underestimation of \\
the radar measurements
\end{tabular}




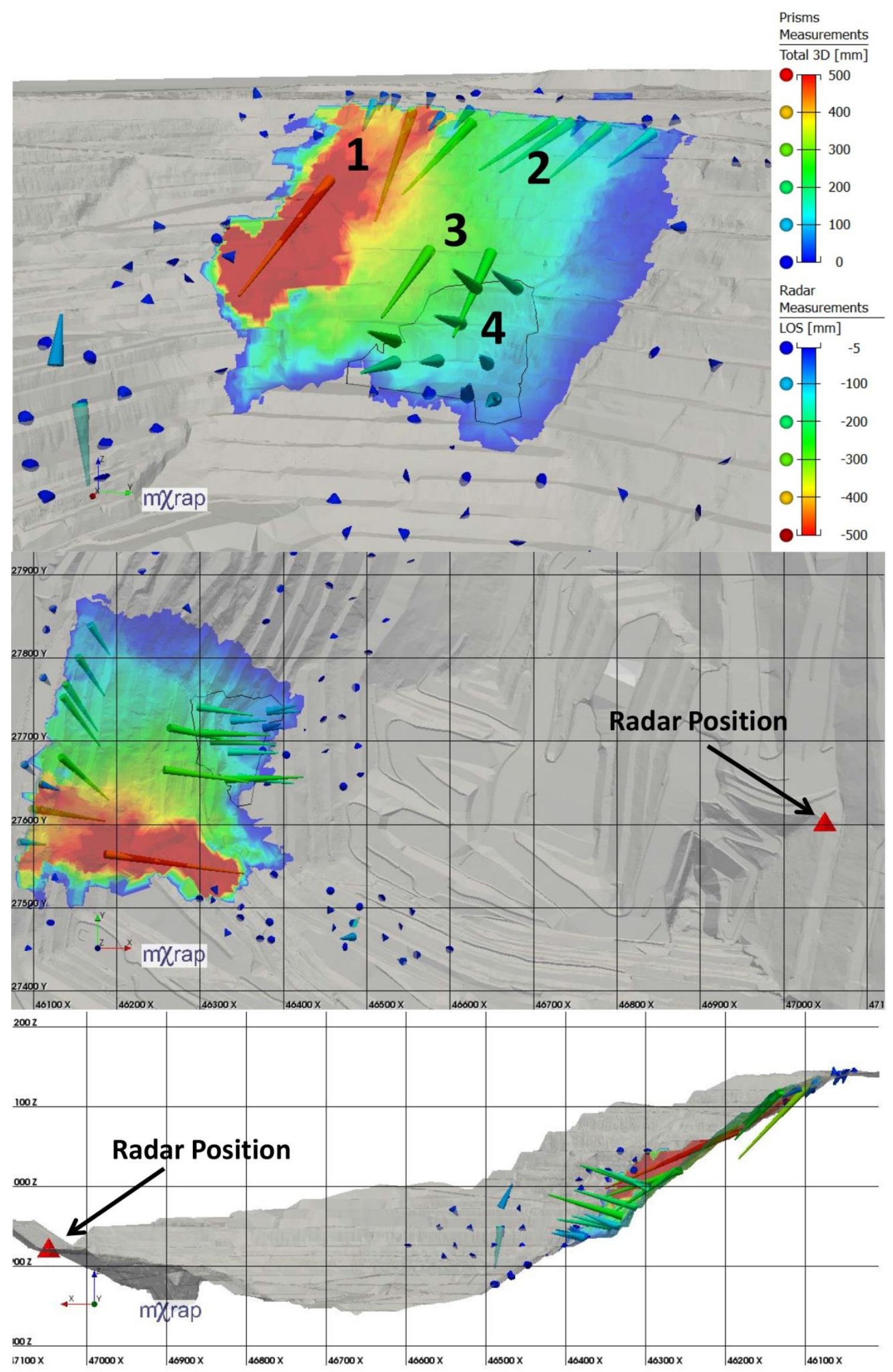

Figure 2 Comparison between prisms and radar monitoring data (1-6 March 2014) 
Two particular aspects can be noticed:

- Near the crest of the pit there is an underestimation of the radar measurements between 20 and $30 \%$.

- It can be observed that there is a rotation of the displacement vector between the crest and the surface above the CBX, but unfortunately no boundaries can be identified between the two areas.

\section{Experimental set-up and data interpretation}

For the experiment, two Reutech ground-based real aperture radars were deployed. The first instrument was located between 500 and $970 \mathrm{~m}$ from the SW wall, with a resolution of measurement grid of approximately $3.6 \times 6 \mathrm{~m}$. The second unit was placed at the top of the east pit wall, with a distance from the SW wall between 780 and $1,250 \mathrm{~m}$ and a resolution of approximately $4.9 \times 7 \mathrm{~m}$. This site was chosen in order to be aligned with the direction of the movement at the crest of the pit and to provide a good overlap between the two radar measurements.

The first radar has been continuously recording in the same position since February 2014, while the second instrument was only deployed from the 25 October to 3 November 2014. For this reason, the two datasets were first resampled in time, in order to synchronise the measurements on the same time window. The dates chosen were between the 25 October at $1710 \mathrm{~h}$ and 30 October at $2350 \mathrm{~h}$, with a time difference between instruments of only few minutes. Subsequent to that, the measurement grids were projected onto the digital elevation model (DEM) to provide consistent points.

The data were imported in $\mathrm{mXrap}$ and the displacements for the time window selected were calculated for each radar unit and visualised in 3D (Figure 3). One of the first challenges was to match the two grids. For this reason, an algorithm was implemented. Site 2 data were used as a master grid, as the spacing between the points is greater, while Site 1 was used as a slave grid. For each point of the master grid, the algorithm searches for the closest 20 points within 10 metres and calculated the inverse distance weighted average displacement. Once the calculation was done, the value was mapped on the relative point of the master grid. In this way, it was possible to match 3,705 points on a common grid.
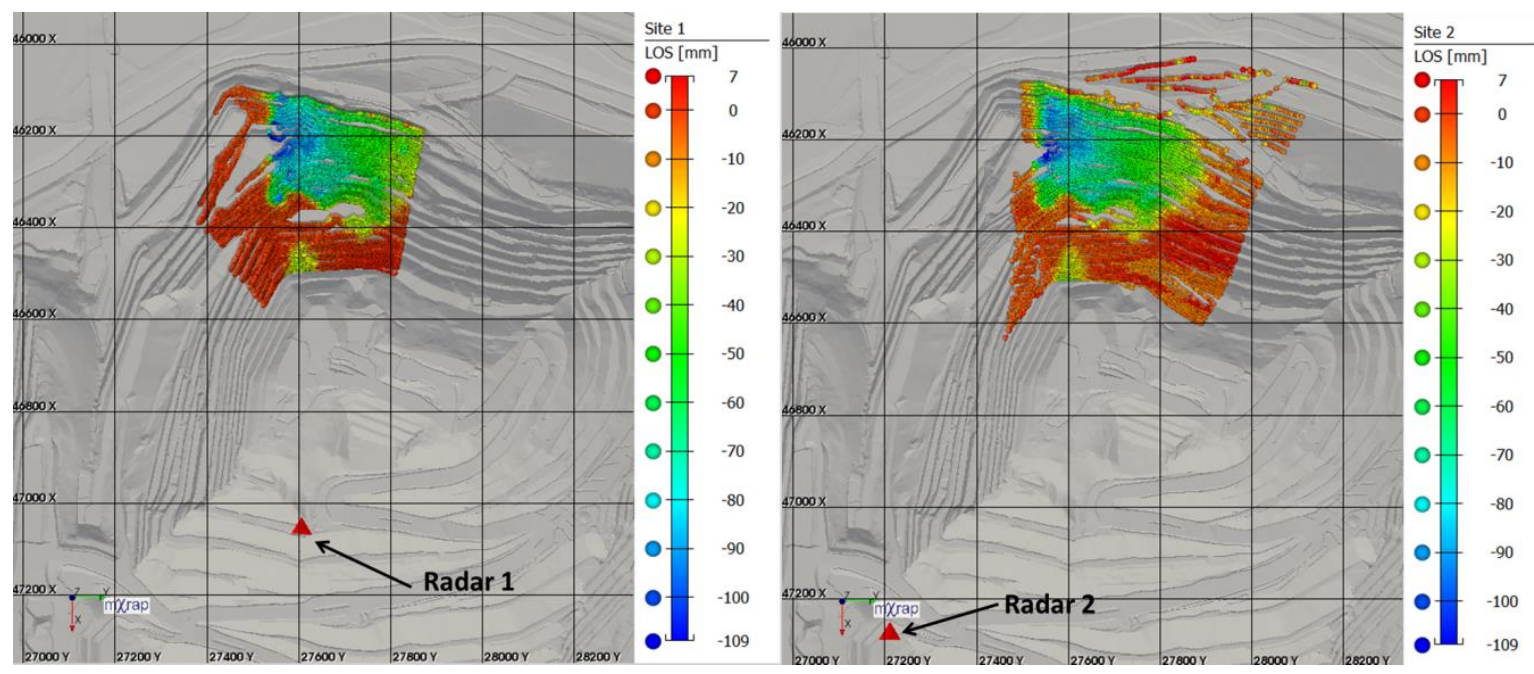

Figure 3 Radar measurements from Sites 1 and 2

As proposed by Severin et al. (2014), the displacement vectors along the LOS and the planes perpendicular to LOS were calculated. In absence of a third radar unit to get a third plane and solve the mathematic solution, a first attempt was done following the former work method. For each point of the two grids the z-component of the displacement along the LOS was calculated. Then, the elevation values for the two radars were weighted based on the total displacement. Those value were used to obtain the third plane of equation $\mathrm{z}=$ weighted elevation value. 
In order to verify the quality of the method, the results were compared with the available prism data. The analysis has shown that there is a good correlation between the magnitude and azimuth from the prism and the surrounding points on the grid. Generally, the errors are within $10 \%$. However, the dip is highly underestimated (more than $80 \%$ ). The main reason is due to the fact that except in the CBX block the vector of movement are steeper than the LOS, with a consequent partially underestimation the elevation values.

In order to overcome this limitation, a different approach was explored. An algorithm was created to interpolate the difference in elevation from the prism network (Figure 4). For each point of the grid the software searches for the closest five prisms within $100 \mathrm{~m}$. Then, the elevation value is weighed based on the inverse distance and mapped on the grid. Finally, the value obtained was combined with the two radar measurements in order to solve the triangulation.

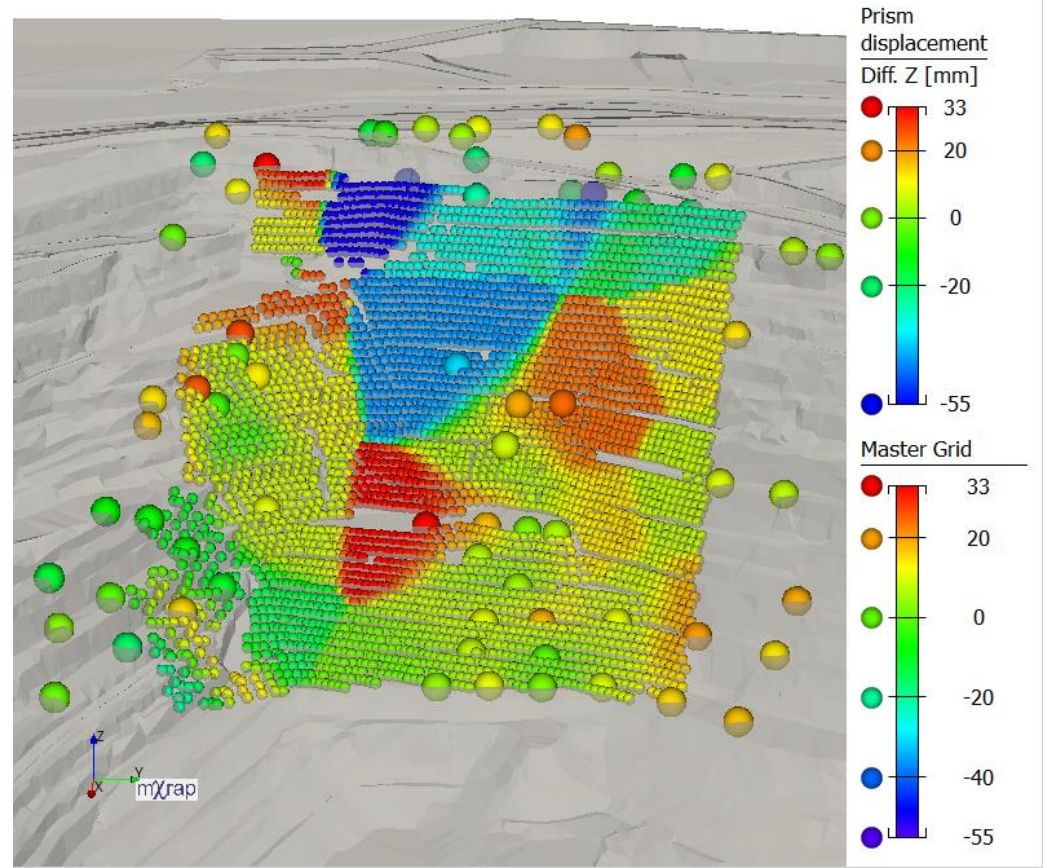

\section{Figure 4 Interpolation of z-component from the prisms map}

\section{Discussion}

As a result of the analysis discussed in Section 3, the experimental method has allowed us to produce a full 3D displacement map for the slope (Figure 5). For each point of the grid not only the magnitude, but also the vector of movement can be observed. A comparison with the prism available has shown that there was a good correlation of the data (error within 10\%) and the issues with the underestimation of the dip of the vector have been overcome.

However, it is still important to notice that a few sources of error cannot be ignored:

- The elevation variation has been estimated from the prism data and the accuracy in the $\mathrm{z}$-component is lower than in $\mathrm{x}$ and $\mathrm{y}$.

- Reflection of the radar signal and consequently accuracy of the measurements are a function of the angle of incidence with the slope (Figure 6). This is quite clear on the bottom left part of Figure 5, where the prisms and radar monitoring don't match at all due to the acute reading angle. 


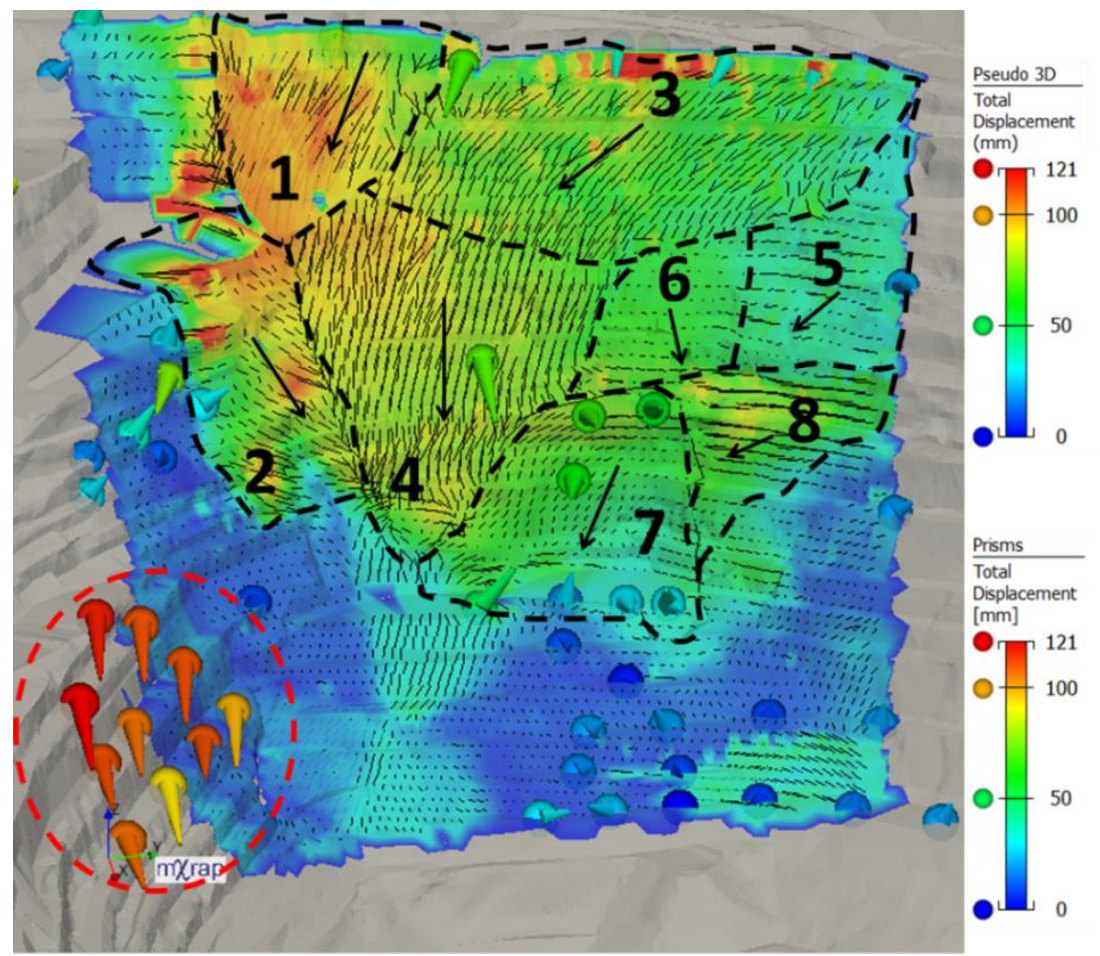

Figure 5 Final results and identification of the subareas based on the displacement vectors. The circle identifies the area were radar and prisms do not match
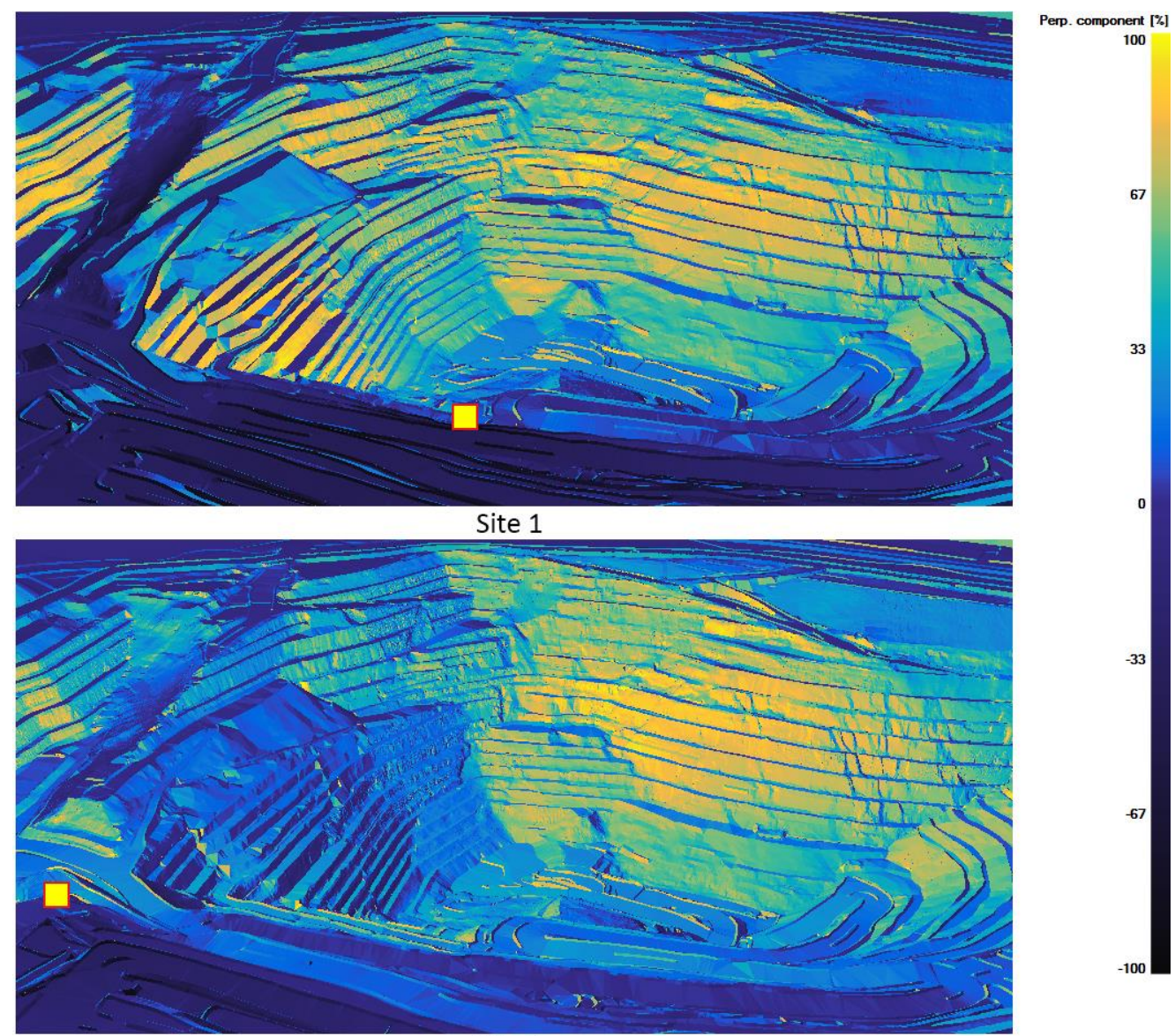

Site 2

Figure 6 Radar component of movement for Sites 1 and 2, assuming movement is perpendicular to surface, with yellow (100\%) (courtesy of Reutech) 
It can be observed from Figure 5, that the slope can be divided in eight different sub-areas, based on the direction of vector movements. For each area, the average displacement for the period was considered and the displacement vectors calculated (Table 2).

The results of the experiment highlighted the very complex kinematics of the slope. Surface deformations are more likely related to the weathering processes affecting the shales, causing the breaking down of the rocks. Different authors (Taylor \& Smith 1986; Walkinshaw \& Santi 1996; Alonso \& Pineda 2006) have outlined how shales are subjected to disintegration and strength reduction, caused by unloading and the wetting/drying cycle. Swelling of clay minerals can rapidly deteriorate rock properties, generating severe damage to the rock mass near the surface. This kind of process can also be observed in the shales at Century. After a few months that core samples are left in an exposed environment, they appear totally disintegrated. That could be explained by the abundance of montmorillonite in the rock that facilitates the absorption of water and subsequent expansion of the clay minerals.

Table 2 Average total displacement magnitude and vectors for different areas obtained, combining two radars and prisms

\begin{tabular}{cccc}
\hline Area \# & Average total displacement $(\mathbf{m m})$ & Azimuth $\left(^{\circ}\right)$ & Dip $\left(^{\circ}\right)$ \\
\hline 1 & 95.3 & 120 & 30 \\
2 & 90.6 & 87 & -15 \\
3 & 70.5 & 139 & 24 \\
4 & 87.6 & 113 & 24 \\
5 & 38.7 & 115 & -20 \\
6 & 62.7 & 91 & -22 \\
7 & 68.7 & 120 & -16 \\
8 & 80.1 & 158 & -15 \\
\hline
\end{tabular}

\section{Conclusion}

In this paper, the authors present a method for combining data from two radars and a set of prism measurements in order to obtain an interpretation of the full 3D surface displacement of a pit slope. From this work, it is clear that:

1. Traditional prism and radar monitoring in the case of complex 3D instabilities may not be able to provide a full comprehension of the kinematics of the slope movements.

2. Even though the method proposed in previous research using two radars can offer a more detailed image of magnitude and vector of displacement for the entire slope, certain limitations can be outlined. In particular, an underestimation of the dip of the vectors was found in the case that vectors are steeper than LOS.

3. Prisms data can be integrated in the previous method in order to achieve more accurate results.

4. The experiment has helped to obtain a much clearer image of the slope, suggesting complex kinematics linked with the surface degradation of shales.

\section{Acknowledgement}

We are grateful to MMG Limited's Century Mine for providing access to the mine and the logistic support. We thank Reutech Mining Division, in particular Anton Joubert, for the use of the instrumentation and the useful discussion on radar techniques. The University of Western Australia is also acknowledged for its 
scholarship contribution during my PhD candidature. The help of Paul Harris and the mXrap team for assisting in scripting the necessary algorithms into mXrap is also gratefully acknowledged.

\section{References}

Alonso, EE \& Pineda, JA 2006, 'Weathering and degradation of shales: experimental observations and models of degradation', in J Montero \& JE Colmenares (eds), Proceedings of the 6th South American Conference on Rock Mechanics, Universidad Nacional de Colombia, pp. 249-296.

Broadbent, GC, Andrews, SJ \& Kelso, IJ 2002, 'A decade of new ideas: geology and exploration history of the Century Zn-Pb-Ag deposit, Northwestern Queensland, Australia', in RJ Goldfarb \& RL Nielson (eds), Integrated methods for discovery: global exploration in the twenty-first century, Society of Economic Geologists, Inc., Special Publication 9, pp. 119-140.

Harris, PC \& Wesseloo, J 2015, mXrap v5 software, Australian Centre for Geomechanics, The University of Western Australia, http://mxrap.com/

Hawley, M, Marisett, S, Beale, G \& Stacey, P 2009, Performance Assessment and Monitoring, in J Read \& P Stacey (eds), Guidelines for open pit slope design, CRC Press, Boca Raton, FL, pp. 327-379.

Hendersonhall, BD, Lucas, D, Kerr, N \& Pennisi, C 2010, 'Practical Management of Progressive Large Failures at Minerals and Metals Group Century Mine', Proceedings of the Seventh Large Open Pit Mining Conference, The Australasian Institute of Mining and Metallurgy, Melbourne, pp. 15-30.

Kurukuk, N \& Sweeney, E 2012, 'Slope Stability Assessment at an open pit mine in Northwest Queensland, Proceedings of the 9th ANZ Young Geotechnical Practitioners Conference (9ANZYGPC), Australian Geomechanics Society, Barton, 9 p.

Little, MJ 2006, 'Slope monitoring strategy at PPRust open pit operation', Proceedings of the International Symposium on Stability of Rock Slopes in Open Pit Mining and Civil Engineering, The South African Institute of Mining and Metallurgy, Johannesburg, pp. 211-230.

Pieraccini, M 2013, 'Real beam vs. synthetic aperture radar for slope monitoring', Proceedings of the Progress in Electromagnetics Research Symposium (PIERS), The Electromagnetics Academy, Cambridge, MA, pp. 1627-1632.

Severin, J, Eberhardt, E, Leoni, L \& Fortin, S 2011, 'Use of ground-based synthetic aperture radar to investigate complex 3-D pit slope kinematics' in E Eberhardt \& D Stead (eds), Proceedings of the 11th International Symposium on Rock Slope Stability in Open Pit Mining and Civil Engineering, Canadian Institute of Mining, Metallurgy and Petroleum, Westmount, Quebec, pp. 18-21.

Severin, J, Eberhardt, E, Leoni, L \& Fortin, S 2014, 'Development and application of a pseudo-3D pit slope displacement map derived from ground-based radar', Engineering Geology, vol. 181, pp. 202-211.

Taylor, RK \& Smith, TJ 1986, 'The engineering geology of clay minerals: swelling, shrinking and mudrock breakdown', Clay Minerals, vol. 21, pp. 235-260.

Walkinshaw, JL \& Santi, PM 1996, 'Shales and other degradable materials', in AK Turner \& LR Schuster (eds), Landslides: investigation and mitigation, Transport Research Board, National Research Council, Washington DC, pp. 555-576.

Waltho, AE \& Andrews, SJ 1993, 'The Century zinc-lead deposit, Northwest Queensland', in IJ Duncan (ed.), Proceedings of the Australasian Institute of Mining and Metallurgy Centenary Conference, Australasian Institute of Mining and Metallurgy, Carlton, pp. 41-61. 
